\title{
Redes sociais e a promoção de diálogo entre israelenses e palestinos
}

The social networks and dialogue promotion between Israelis and Palestinians

Rafaela Barkay ${ }^{1}$

Doutoranda do Programa de Estudos Judaicos e Árabes do Departamento de Letras Orientais da FFLCH-USP, tem como tema de pesquisa a interação entre israelenses e palestinos em programas de promoção de diálogo sob o olhar da Psicologia Poltica. Recebe apoio financeiro na concessão de bolsa de estudo pela Coordenação de Aperfeiçoamento de Pessoal de Nivel Superior (CAPES). Moderadora de grupos de diálogo ente Email: refaphes
RESUMO: 0 presente estudo trata da interação online entre israelenses e palestinos observada em um grupo de discussão no Facebook durante os anos de 2014/2015. Ao explorar o potencial de diálogo entre indivíduos separados fisicamente promovido pelo advento das redes sociais, e buscar fundamentação em modelos desenvolvidos na área de Resolução de Conflitos, pretende-se demostrar a possibilidade de encontro entre estas duas populações em conflito, mesmo que as barreiras físicas e as políticas de Estado o impeçam de ser presencial.

Palavras-chave: Redes Sociais; Conflito Israelense-Palestino; Reconciliação; Diálogo.

ABSTRACT: This study deals with the online interaction between Israelis and Palestinians observed in a discussion group on Facebook during the years 2014/2015. By exploring the potential to dialogue between physically separated individuals promoted by the advent of social networks, and on seeking justification in models developed in the Conflicts Resolution area, we intend to demonstrate the possibility of encounter between these two populations in conflict, even if the physical barriers and state policies prevent it from being in-person.

KEYWORDS: Social Networks; Israeli-Palestinian conflict; Reconciliation; Dialogue. 


\section{Introdução}

$\mathrm{N}^{2}$

a esteira dos protestos por justiça social que tomaram conta das ruas das principais cidades de Israel entre agosto e outubro de 2011, começaram a despontar movimentos online em prol da paz na região. Se as primeiras manifestações em Tel Aviv foram organizadas através de páginas no Facebook para dali ganhar as ruas, foi precisamente neste ambiente, que mais tarde, esforços de aproximação entre os supostos inimigos ganharam corpo.

Em novembro de 2012, durante a operação Pilar de Defesa, como Israel denominara a intervenção militar em Gaza, tive a oportunidade de entrevistar e acompanhar o trabalho de líderes de iniciativas pela paz que atuavam nas redes sociais. Como observadora participante, não somente estabelecia laços pessoais, como atuava na administração e mediação do grupo de discussão então estudado, e acompanhava a atividade das três comunidades ${ }^{1}$ analisadas.

A participação individual no Facebook é vinculada à criação de um perfil pesoal, por meio do qual se pode, entre outros recursos, acompanhar as publicações de comunidades ligadas a um produto, causa ou indivíduo, ou aderir a grupos de discussão específica. Se, por um lado, as comunidades permitem o aceso a um público mais amplo, os grupos propiciam maior interação entre os usuários. Na primeira forma, o conteúdo é alimentado por um gerente, e reproduz a estrutura de blogs, tratando de um assunto ou personagem central que pode permitir ou não comentários de acordo com as configurações eleitas. A segunda opção estrutural aqui assinalada permite o estabelecimento de discussões que podem acontecer em tempo real ou tardiamente através de comentários, e sobre vários assuntos simultaneamente. A privacidade de um grupo de discussão é definida pelo administrador, que pode também eleger outros participantes para compartilhar a gerência. (BARKAY, 2013, p. 5).

\footnotetext{
1 As comunidades são também conhecidas como páginas, tratadas neste caso como sinônimos.
}

Recuero afirma que "as mídias sociais podem ajudar a promover a democracia através do contato com diferentes opiniões, ajudar na educação por meio da disseminação de informações, e também desafiar o discurso dominante ao propor e legitimar ideias diferentes." - mas questiona - "elas fazem isto?” (RECUERO, 2015, p. 2, tradução nossa). As propostas que observei pregavam a humanização do inimigo através do estabelecimento de laços pessoais em interações na rede, e seus líderes entendiam que a paz também deveria fazer parte das demandas por justiça social, uma vez que uma parcela significativa do orçamento do Estado de Israel é aplicada na defesa, em operações militares e na manutenção dos assentamentos nos territórios ocupados, em detrimento de outras áreas tais como saúde, educação e moradia, o que contribuiria para a deterioração destes setores. Naquele momento, ousando transpor os limites físicos que os separavam, israelenses e palestinos começavam a estabelecer os primeiros contatos virtuais entre si, através da internet em geral e das redes sociais em particular.

Diversos grupos e Organizações não Governamentais já atuavam desde os anos 1990 e primeiros anos da década de 2000 na aproximação entre as duas populações in loco. No entanto, desde a retirada israelense da Faixa de Gaza em 2005 e posterior fechamento das fronteiras após a ascensão do Hamas ao poder em 2007, o encontro físico entre israelenses e palestinos desta região tornou-se impossível ou muito incipiente, situação que se mantém até hoje e que reforça a importância dos contatos no ambiente virtual. Se antes de 2007 o convívio destas duas populações se dava principalmente por relações de trabalho, esta possibilidade cessou quase que por completo, limitando seu encontro a raros casos de obtenção de autorização para tratamento médico em Israel ou diante de situações muito específicas. Os palestinos da Cisjordânia, um pouco mais acostumados ao convívio com israelenses por sua participação em grupos ou atos pela promoção da paz, pela prática de turismo ou por trabalhos temporários em Israel, ambos possíveis em 
alguns casos mediante obtenção de permissão do exército², arriscavam-se mais nas aproximações online. À época, os palestinos de Gaza ainda tinham muito medo de ser descobertos em seu contato com israelenses, e sofrer represálias por parte de membros do governo local ou de seus apoiadores. Neste sentido, comunidades como Palestine Loves Israel ${ }^{3}$ desempenharam um importante papel como ponte entre as duas populações. Mesmo sem se identificar, muitas vezes usando somente o primeiro nome ou um apelido e nenhuma fotografia pessoal, timidamente esta população dava os primeiros passos na direção do "outro" desconhecido. Se por um lado, como aponta Recuero:

[...] o Facebook torna mais fácil a manutenção das conexões sociais já existentes, por outro, este não é o único valor discutido nos sites de rede social. Ao permitir a manutenção, ela também facilita a associação com outros atores que não conhecemos ou que conhecemos muito pouco e com os quais dificilmente teríamos oportunidade de aprofundar os laços sociais (RECUERO, 2014, p. 117).

O surgimento das redes sociais mostrou-se como importante meio de aproximação entre os dois grupos, no entanto, principalmente em momentos de crise como na operação militar de 2012, israelenses e palestinos acusavam-se mutuamente, e não raro discussões acaloradas tomavam conta do cenário, demostrando o quanto os laços de confiança ainda eram frágeis. A atuação destas iniciativas, entretanto, não somente se manteve, como cresceu e serviu de inspiração para inúmeras outras, e pouco a pouco as faces e histórias de vida se revelavam.

2 Palestinos da Cisjordânia não têm permissão para circular livremente em Israel. Para tanto é necessário a obtenção de autorização do exército, nem sempre concedida. Israelenses, por sua vez, não têm parestina Muitos do para Palestina. Mutos dos encontros organizados por fóruns e ONGs se realizam em áreas C da Cisjordânia, permite também o livre acesso de palestinos.

3 https://www.facebook.com/pages/Palestine-Loves-Israel/209640082469004?fref=ts
Recuero afirma que as ferramentas que o Facebook disponibiliza para a participação na conversação são usadas através de um acordo tácito entre os grupos envolvidos, podendo construir laços sociais mais fortes e de confiança, possibilitando que se aumente a distância social entre os membros na rede ao se criar grupos mais privados, o que seria associado a uma maior segurança do ambiente (RECUERO, 2014, p. 122). No início de 2014 criei no Facebook um grupo de discussões "secreto", ou seja, do tipo cujas configurações permitem que somente seus membros tenham acesso tanto às discussões como à lista de participantes, modalidade que permitia que os palestinos de Gaza se manifestassem com maior liberdade, e para o qual os convidei ao diálogo palestinos da Cisjordânia, de Gaza e de Jerusalém Oriental, palestinos e judeus israelenses e indivíduos de ambas as diásporas. Optei por trabalhar com um grupo numericamente inferior a outros grupos similares na rede ${ }^{4}$, mas que concentrasse indivíduos que haviam previamente demonstrado compartilhar do mesmo desejo de busca pela aproximação, onde estabeleci como proposta o diálogo aberto e franco, tendo como única restrição o cuidado em não se publicar imagens ou textos violentos ou que pudessem ser percebidos como ofensivos. Um texto compartilhado por um dos membros, que fazia a diferenciação entre o diálogo e o debate, viria a servir de guia para as interações. Nele assim descrevem Len e Libby Traubman:

Nem toda a comunicação é um diálogo. Nós escolhemos como queremos nos comunicar. Existe a comunicação banal que pode soar desinteressante, opressiva, ou deprimente. Isto é comum quando os participantes estão tentando evitar o conflito, a intimidade ou surpresas. Reflete-se em extrema polidez, reuniões firmemente controladas e relacionamentos alienados. A comunicação antagônica, que inclui o debate, é uma conversa ou discussão que não consegue ir além do conflito. [...] As discussões são mais parecidas

${ }^{4}$ O grupo se mantém até hoje com uma média de 200 a 220 membros, ao passo de que outros grupos similres chegam a agregar mais de 5.000 indivíduos. 
com jogos de pingue-pongue, onde os participantes rebatem suas ideias muito sólidas e posições bem defendidas para frente e para trás. Em comparação, o diálogo é uma comunicação criativa que envolve a diversidade e a imaginação. É uma exploração mútua que cria uma maior compreensão compartilhada, ou seja, gera conexão e possibilidade. 0 resultado é um melhor relacionamento e uma nova inteligência social (TRAUBMAN; TRAUBMAN, s/d) ${ }^{5}$.

Rapidamente o grupo criou uma identidade e ritmo próprios, onde pessoas com diferentes perspectivas trocavam impressões sobre fatos da atualidade na região com foco no conflito israelense-palestino, e buscavam no discurso do outro o complemento para a narrativa conhecida até então. Laços de amizade se formaram extrapolando os limites do grupo, até que uma nova guerra ${ }^{6}$, desta vez mais longa e mais sangrenta, teve início em junho do mesmo ano.

Diferentemente de 2012, uma segunda guerra paralela rapidamente alastrou-se no mundo virtual. Uma enxurrada de imagens e textos violentos tomou conta dos perfis pessoais, comunidades e grupos do Facebook, assim como em outras redes como o Twitter, Instagram e outras, levando a um intenso desgaste emocional de seus seguidores. Atordoados e tomados pela angústia, muitos procuravam por argumentos de auto-defesa, e a atribuição da culpa ao outro, demonizado e despido de qualquer traço de humanidade impediam a possibilidade de diálogo.

Se o lugar-comum nas redes sociais era o da reprodução do terror vivido em campo, aqueles que de alguma forma já vinham estabelecendo relações virtuais que desvinculavam o outro da imagem de inimigo, foram atores de uma vivência paralela de cooperação e cuidado mútuo. As primeiras manifestações deste novo ciclo de violência deram-se com o sequestro e morte de três jovens judeus israelenses na Cisjordânia seguido da tortura

5 Todos os trechos citados a partir deste ponto foram traduzidos por mim.

6 Denominada por Israel de "Operação Margem Protetora". e assassinato de um jovem palestino. Imediatamente após a publicação da notícia de que os corpos dos três adolescentes haviam sido encontrados, palestinos envolvidos em grupos de interação online apressaram-se em manifestar as condolências aos amigos israelenses e judeus ao redor do mundo em demonstração de solidariedade. Alguns palestinos da Cisjordânia chegaram a prestar visita a uma das famílias enlutadas, e quando no dia seguinte, foi anunciado o assassinato do jovem palestino, mais de 500 ativistas israelenses prontamente se organizaram nas redes sociais para visitar a família da vítima em Jerusalém Oriental.

À medida em que a guerra avançava, os números de mortes e destruição cresciam e os ataques nas redes sociais se intensificavam, aqueles que já estavam envolvidos no ativismo pela paz reforçavam seus laços. Nosso pequeno reduto no Facebook, assim como outros espaços que pregavam a coexistência entre israelenses e palestinos, eram ilhas de descanso, apoio, diálogo e troca de informações. Alarmado pelo anúncio do Hamas no canal de televisão local, um jovem de Gaza apressou-se em alertar os israelenses do grupo, frente à ameaça do lançamento de mísseis a Tel Aviv. A garota de Gaza assustada durante um bombardeio, compartilhou seu desespero, e a professora israelense, moradora de uma comunidade agrícola na fronteira, propôs um trabalho conjunto de educação pela paz assim que a guerra tivesse um fim. Da minha parte, acompanhei vários jovens de Gaza durante bombardeios. 0 que me restava era procurar acalmá-los e preservar um mínimo fio de esperança pela vida.

Ativistas de todos os cantos naturalmente criaram uma rede de apoio virtual, onde buscavam e ofereciam energia para enfrentar o horror diante do que acontecia ao redor. Israelenses e palestinos estavam cada vez mais enfraquecidos e confusos à medida em que a guerra avançava, e ainda assim, acolhiam-se mutualmente. Uma das integrantes do grupo, moradora da região sul de Israel, a mais castigada pelos ataques de mísseis vindos de 
Figura 1 - Palestino de Gaza alerta israelenses no grupo de diálogo no Facebook sobre ataque iminente

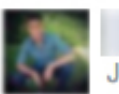

July $12 \cdot$ Edited $\cdot$ 且

Open dialogue Israel/Palestine

IMPORTANT

Guys ....Hamas is declaring in it's official TV channels and radio that 9:00 PM it will bomb Tel Aviv :

Guys I don't know if they are gonna make do it or not but anyway anyone in Tel Aviv please be careful :)

About 20 minutes left ...I don't wanna sound like I spread fear but please be careful :)

Love you all...stay safe $\bigcirc$

Like C Comment $\cdot \mathbb{B} 12 \square 3$

Figura 2 - Palestina de Gaza compartilha momento de desespero no grupo de diálogo no Facebook

Strange smell , strange light, and strange sound !!! From a rocket fall near
by my house in an agricultural land ...
I cannot differentiate between the rockets which is raining over us till now !!
I still hearing multiple explosions in this crazy midnight !
I wish that our children can sleep safely and peacefully without any sense
of fair !
So, If we do not have shelters to protect ourselves
where is to go ?!
People who live in my nighborhood escaped to the streets !
Keep praying for all innocent people in \#Gaza please !!
Like - Comment - 7 715

Gaza, relatou que durante um curto período de cessar-fogo encontrara o pai de uma criança que frequenta a mesma escola que seus filhos, e que tem como proposta pedagógica a educação conjunta de crianças palestinas e judias. "Ele me disse que toda vez que soava a sirene anunciando um novo ataque e tinham que correr para o abrigo antiaéreo, o filho de seis anos de idade levava uma boneca, e conversava com ela"-relatou. Ao ser perguntado sobre o motivo de tal atitude, o menino respondera que estava preocupado com as crianças de Gaza, que naquele momento não tinham sequer um abrigo para onde correr.

\section{Reflexões}

\subsection{Diálogo e Reconciliação}

A área de Resolução de Conflitos busca desenvolver métodos e processos específicos, visando a comunicação ativa entre indivíduos que enfrentam situações de discordância, sejam elas no plano particular ou coletivo. Dedicase à problematização destas interações e à proposição de ferramentas que auxiliem na aproximação e no entendimento.

Desta maneira, indivíduos em contextos de conflito ou que tenham passado por traumas sociais graves, podem ser beneficiados pela criação de ambientes seguros que facilitem o estabelecimento de um diálogo honesto através do emprego de algumas regras e diretrizes básicas, dentre elas, o estabelecimento de relações empáticas e de simetria de poder dentro do grupo, onde a atenção às especificidades de cada subgrupo sejam consideradas de forma igualitária visando fortalecer identidades multiculturais, garantindo que todos os participantes sejam tratados com igual respeito. Entendendo a escuta empática como a capacidade de projetar-se na personalidade do outro, a fim de compreender melhor suas emoções ou sentimentos, Chaitin (2003) aponta: 
Ajudar indivíduos a se tornar ouvintes empáticos tem se mostrado como uma importante habilidade para a comunicação interpessoal e inter-grupos entre adversários antigos ou atuais. Esta, talvez, seja a habilidade mais importante e talvez a mais difícil para se ensinar ou adquirir, uma vez que os indivíduos estão muitas vezes ocupados pensando em sua resposta ou no que eles gostariam de dizer quando chegar a sua vez, tornando-se desatentos para quem está falando. Além disso, se o orador está tocando em questões e experiências desconfortáveis para o(s) ouvinte(s), se eles sentem que estão sendo responsabilizados, ou porque o estilo e o conteúdo da comunicação é emocionalmente difícil de se lidar, a escuta empática fica ainda mais difícil. Não se deve esperar que a escuta empática seja alcançado de uma hora para outra ou que todos os participantes dominem este tipo de escuta; este é um processo dinâmico e contínuo, e caracterizada por altos e baixos (CHAITIN, 2003).

Em muitas ocasiões foi necessário que nos voltássemos às diretrizes básicas do grupo, buscando diferenciar os padrões de debate e diálogo segundo as definições que havíamos assumido, especialmente diante da adesão de novos membros. A percepção desta perspectiva demanda a disponibilidade do indivíduo em buscar o refinamento na auto-percepção e na consciência do outro, e eventualmente alterar padrões de comportamento arraigados, mesmo dentre aqueles já acostumados a fazer parte de outros grupos virtuais que tivessem como objetivo a construção de uma cultura de paz. Assim, recorrendo à diferenciação proposta por Traubman e Traubman (s/d), retraçávamos nossa rota:

- O diálogo é colaborativo: dois ou mais lados trabalham juntos em direção a um entendimento comum. 0 debate é de oposição: dois lados se opõem uns aos outros e tentam provar que o outro está errado.

- No diálogo, o objetivo é encontrar um terreno comum. No debate, ganhar é o objetivo.

- No diálogo, ouve-se o outro(s) lado(s) a fim de compreender, aprender, encontrar significado, e talvez encontrar um acordo. No debate, escuta-se o outro lado a fim de encontrar falhas e contrariar seus argumentos e talvez não se aprenda nada.
- O diálogo amplia e, possivelmente, muda o ponto de vista de um participante. O debate afirma o próprio ponto de vista.

- O diálogo revela premissas para reavaliação. 0 debate defende suposições como verdades.

- O diálogo provoca introspecção sobre a própria posição. 0 debate provoca crítica à outra posição.

- O diálogo abre a possibilidade de se chegar a uma solução melhor do que qualquer uma das soluções originais. 0 debate defende as próprias posições como a melhor solução e exclui outras.

- O diálogo cria uma atitude de mente aberta: uma abertura para estar errado e uma abertura à mudança. 0 debate cria uma atitude de mente fechada, uma determinação em estar certo.

- No diálogo, cada um submete seu melhor pensamento, sabendo que as reflexões de outras pessoas vão ajudá-lo a melhorar, em vez de destruí-lo. No debate, cada um defende-se, com o desafio de mostrar que está certo.

- O diálogo exige que cada um suspenda temporariamente suas crenças. 0 debate chama para o indivíduo a investir todo o coração em suas crenças.

- No diálogo, há uma procura por acordos básicos. No debate, uma procura por diferenças gritantes.

- No diálogo, procura-se por pontos fortes em outras posições. No debate, procura-se por falhas e fraquezas nas demais posições.

- O diálogo envolve uma preocupação real com o outro e procura não alienar ou ofender. 0 debate envolve uma neutralização da outra posição sem que se concentre em sentimentos ou relacionamento e muitas vezes deprecia-se o outro.

- O diálogo assume que muitas pessoas têm partes da resposta e que juntos pode-se construir soluções viáveis. 0 debate assume que há uma resposta certa e que alguém a detém.

- O diálogo permanece em aberto. 0 debate implica uma conclusão. (TRAUBMAN; TRAUBMAN, s/d)

Abu-Nimer estudou a aplicação de modelos de Resolução de Conflitos entre populações vindas de diferentes contextos religiosos e culturais, onde considerou a cultura "não como um conjunto de padrões e conceitos estáticos reconhecidos em nível coletivo, mas como o processo social e cognitivo de indivíduos, enfatizando a variedade [de possibilidades] que 
estes encontram" (ABU-NIMER, 1996, p. 687). Ao propor esta construção teórica para a aproximação entre grupos vindos de diferentes contextos sociais, postulou que:

A mudança de atitudes e de comportamentos requer o encontro com o outro, um exercício com sua dinâmica e ferramentas próprias. [...] a escuta, a facilitação e a mediação são usadas para ensinar aos participantes novas tipos de respostas ao encontrar o outro (ABU-NIMER, 1996, p. 694).

A respeito de processos de reconciliação, Bar-Tal afirma que "exigem a construção de relações pacíficas baseadas na confiança e aceitação recíprocas, cooperação e consideração das necessidades mútuas". Diz "não se tratar de um processo formal, por requerer uma mudança de crenças sociais, que pode começar independentemente do processo de resolução de conflitos ${ }^{7}$, antes mesmos que os lados opostos comecem a negociar" (BAR-TAL, 2000, p. 351-362). A busca essencial nas interações do grupo referia-se menos a encontrar respostas para a solução do conflito e mais à quebra de padrões engessados decorrentes de anos de separação e violência. Ao experenciar o estabelecimento de laços de confiança e muitas vezes amizade entre indivíduos, tinha-se em mente a possibilidade de estabelecimento de parcerias que se expandissem para além do mundo virtual.

\subsection{Redes Sociais e Ciberativismo}

As mídias sociais são sistemas projetados para possibilitar a interação a partir da criação colaborativa e do compartilhamento de informação, e podem diferir na forma e no objetivo a ser alcançado, que pode ser a partilha de músicas (como o Myspace), imagens (Instagram), publicações editoriais

\footnotetext{
Bar-Tal refere-se aqui a negociações formais promovidas entre governos e/ou lideranças, no entanto, quando utilizo este termo, pretende referir-me a processos de reconciliação entre as populações envolvidas.
}

independentes (os Blogs), entre outros. Dentre as diversas mídias, existem as redes sociais, das quais o Facebook, criado em 2004, se tornou a maior já existente em todo o mundo. Neste ambiente, a liberdade e o alcance de comunicação tornou possível uma grande mudança na estrutura de poder social, permitindo que o cidadão comum gerasse conteúdo e influenciasse pessoas e decisões.

Desde os anos 90 a internet tem se mostrado como importante ferramenta na organização e na divulgação de manifestações políticas. Já no início da década, ativistas do movimento Zapatista no México adaptaram suas mensagens para uma emergente audiência global. No início dos anos 2000, a rede desempenhou um papel significativo como base de movimentos contrários à guerra e em favor da paz, e desde então se firmou como um novo paradigma de comunicação. Kahn e Kellner (2004) descrevem este processo:

Em oposição à estratégia capitalista da globalização de "cima para baixo", subculturas de ciberativistas vêm buscando realizar a globalização de "baixo para cima', desenvolvendo redes de solidariedade e propagando ideias e movimentos de oposição em todo o planeta [...] Estas redes múltiplas de cidadãos e ativistas conectados transformaram as chamadas "massas ignorantes" dos Estados totalitários e poliárquicos em "massas esclarecidas" de personagens socialmente ativos ligados por computadores portáteis, dispositivos digitais pessoais, telefones celulares, pagers e sistemas de posicionamento global (GPS). [...] Obviamente, forças de direita e reacionárias podem, e têm usado a internet para promover suas agendas políticas, assim como, mais recentemente [...] grupos "terroristas" a têm utilizado cada vez mais para promover suas causas. (KAHN; KELLNER, 2004, p. 89).

Uma característica específica das mídias sociais é a possibilidade do anonimato de seus usuários, o que significa que pode-se escrever e opinar sobre publicações usando apelidos ou pseudônimos. "Mesmo que o anonimato seja uma oportunidade para se comentar sobre assuntos delicados, pode também levar a 'flame wars' [ou uma série de comentários raivosos, críticos, 
ou depreciativos trocados por duas ou mais pessoas em uma discussão online] e evitar a responsabilidade [sobre o que foi dito]" (AUVINEN, 2015, p. 6). Outra consequência do amplo alcance das redes sociais foi, como afirmam Edmunds e Turner, a globalização do trauma pois, "significou que os eventos poderiam ser experimentados simultaneamente, transcendendo o tempo e o espaço" (EDMUNDS; TURNER, 2005, p. 573). Desta maneira os ciclos de violência vivenciados localmente entre israelenses e palestinos ganharam uma projeção até então desconhecida.

\subsection{A Nuvem de Tags}

Em agosto de 2014, durante a operação Margem Protetora, Gilad Lotan analisou interações nas redes sociais que tratavam da guerra em Gaza, onde descreveu comportamentos observados na ocasião em que uma escola da UNWRA na cidade de Rafah foi atingida por um ataque israelense, matando quinze pessoas. Israel alegou que seu alvo eram três membros da Jihad Islâmica, movimento fundamentalista islâmico, e que naquele momento passavam em motocicleta na frente da escola.

Lotan estudou a ocorrência de hashtags ${ }^{8}$ em mensagens no Instagram que se referiam a este ataque, e construiu uma nuvem de tags, ou seja, uma representação gráfica destas manifestações, onde a importância relativa de cada termo é retratada através do tamanho da fonte ou cor específica. Neste modelo, termos que apareceram com maior frequência foram representados por um corpo de fonte maior do que aqueles que tiveram uma incidência menor, e a proximidade entre as palavras na nuvem representava a frequência com que apareceram juntas. Lotan utilizou a cor azul para retratar manifestações pró-Israel e a cor verde para aquelas pró-Palestina. O que

8 Hashtags são palavras-chave antecedidas pelo símbolo cerquilha (\#). As hashtags viram hiperlinks dentro da rede, indexáveis pelos mecanismos de busca. O hiperlink, ou somente link, por sua vez, é atalho, caminho ou ligação. Através dos links é possível produzir documentos não lineares interconectados com outros documentos ou arquivos a partir de palavras, imagens ou outros objetos. se vê nesta nuvem é uma intensa polarização e quase nenhuma interação, sendo estas últimas simbolizadas por linhas tênues, quase imperceptíveis.

Há uma diferença clara no quadro quando comparamos um lado do gráfico com o outro. Nenhuma das informações compartilhadas é falsa por si só, mas os usuários escolhem deliberadamente o que desejam amplificar. Esta é uma representação dos seus valores e os valores das suas conexões. As mensagens transmitidas em um lado do gráfico nunca alcançam o outro (LOTAN, 2014).

Figura 3 - Nuvem de tags que representa coocorrência de hashtags em mensagens no Instagram

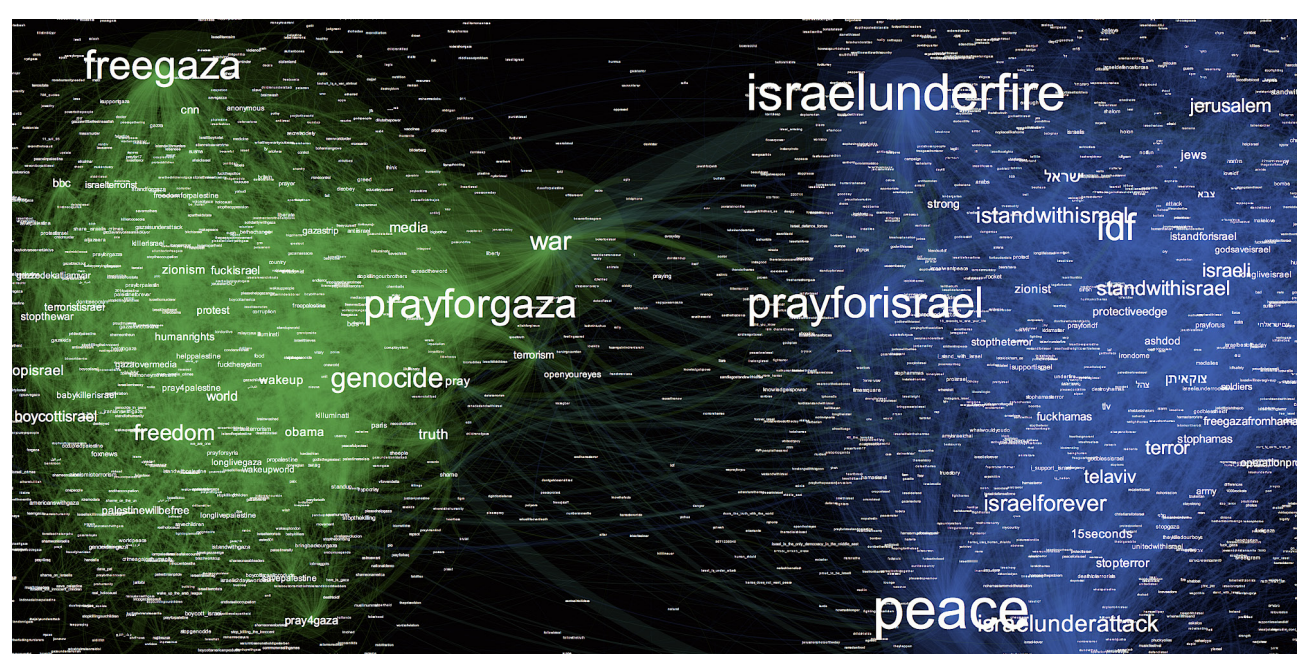

Fonte: LOTAN (2014)

Na prática, sentíamos a diferença entre o ambiente dentro de nosso grupo e fora dele, sendo referido muitas vezes como um porto seguro em um oceano de agressividade. Uma das participantes trouxe como tema de diálogo o ataque israelense que vitimizara as quinze pessoas em Gaza. Sem 
acusações, mas compartilhando a dor, palestinos e israelenses lamentaram a perda de vidas e demonstraram mais similitudes do que diferenças. Sem acesso ao aplicativo que Lotan utilizara para sua pesquisa, nem com pretensão de desenvolver uma incursão densa no campo da estatística, me propus a uma experiência simples ao construir uma nuvem de tags em um aplicativo gratuito, destes disponíveis para o público leigo. A palavra que apareceu em maior destaque foi "paz".

Figura 4 - Nuvem de tags representando a interação dentro do grupo de diálogo no Facebook

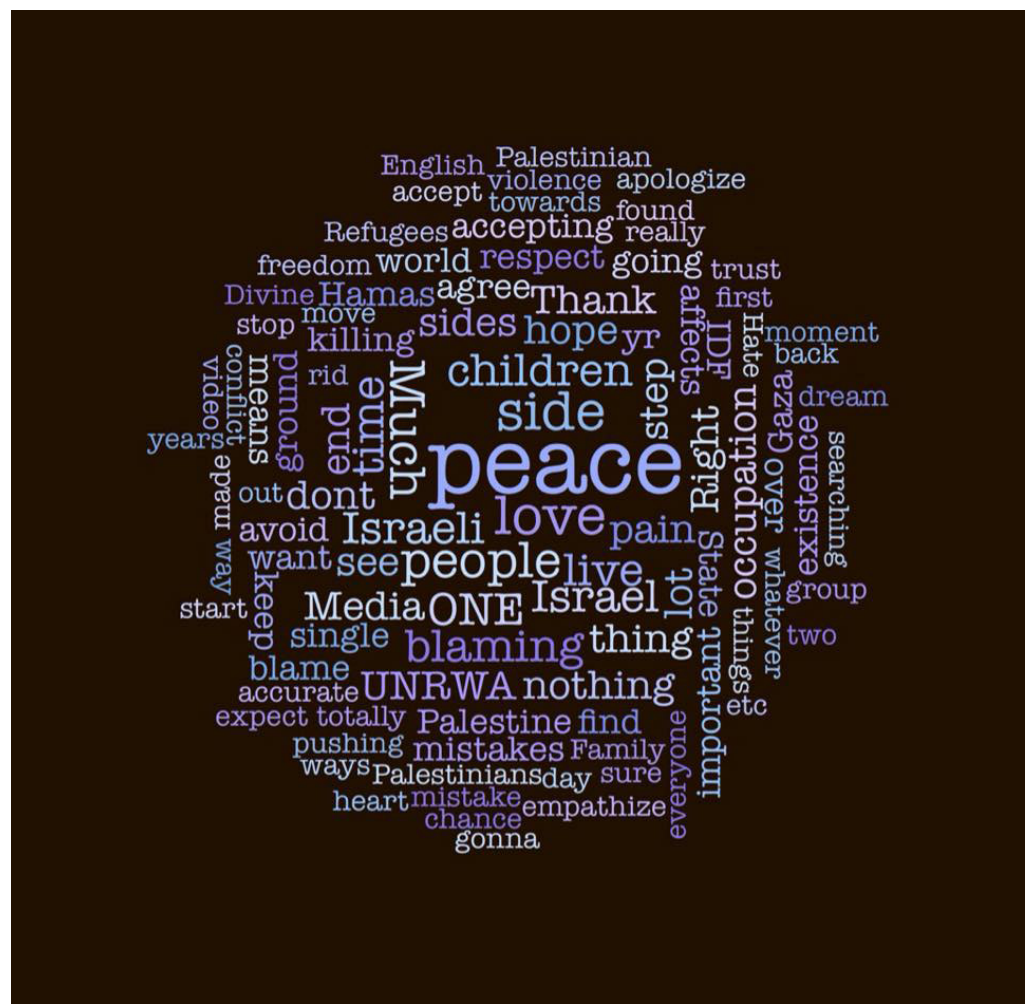

\section{Considerações finais}

Não há dúvidas de que a resolução do conflito israelense-palestino depende de interesses e decisões em outras esferas, às quais a maioria da população não tem acesso direto. No entanto, não será a assinatura de um acordo de paz que trará a cura para traumas pessoais e coletivos. A construção de uma nova percepção do outro demandará tempo e trabalho árduo, e quanto antes for iniciada, melhores as chances de que se atinja bons resultados. Com o final da guerra, a população israelense de um modo geral procurou retomar a vida. A população de Gaza, rapidamente abandonada sob os escombros pelo olhar público mundial, frustrada, traumatizada e sem esperança alguma, recolheu-se ao silêncio profundo, somente audível para aqueles que se encontram muito perto.

Se, como afirma Recuero, "as mídias sociais têm, em muitos aspectos, dado e 'super-poderes' à violência simbólica", e "proporcionado um espaço fundamental para a reprodução de todos os tipos de discursos, inclusive os violentos" (RECUERO, 2015, p. 1, tradução nossa), pode-se afirmar que também há lugar para a promoção do diálogo entre atores distanciados socialmente devido a conflitos nacionais. Este estudo não se tratou de uma pesquisa controlada, tampouco a criação do grupo teve a pretensão de servir a algum propósito acadêmico. No entanto, a observação de resultados sutis que se manifestaram de forma orgânica sugerem que o desenvolvimento de trabalhos mais estruturados que promovam a reconciliação também pode se servir de ferramentas virtuais. Ainda que não substituam encontros presenciais, estas têm o poder de reforçá-los e permitir a convívio entre populações impedidas de tê-lo fora da rede.

Em sua pesquisa, Bachman, Guo e Harp, concluíram que as mídias sociais ajudam seus usuários a ser mais ativos em arenas políticas e cívicas auxiliando a promover o diálogo, e que estas podem tornar-se um fórum 
participativo onde indivíduos com interesses comuns podem se unir, se fortalecer e, finalmente, unir esforços para melhorar suas comunidades. Quase a metade dos militantes pesquisados acreditam que o ativismo na rede se traduz para o ativismo fora dela. (BACHMANN; GUO; HARP, 2012, p. 313-4).

Em nossa experiência, os encontros presenciais entre judeus e palestinos israelenses e aqueles da Cisjordânia se tornaram mais frequentes com o passar do tempo, não acontecendo somente em eventos formais promovidos por grupos locais, mas também em visitas espontâneas. Em relação aos palestinos de Gaza, apesar do encontro fora da rede ainda não ser possível, as interações virtuais ganharam corpo. Em certa ocasião uma jovem israelense se dispôs a trocar aulas de hebraico por outras de árabe, ao que uma palestina de Gaza respondeu prontamente. Não tenho notícias de como vão os estudos, mas a amizade das duas moças floresceu, comunicam-se frequentemente por vídeo através do Skype, onde conversam como qualquer jovem de sua idade. Recentemente a israelense me procurou sem saber como responder à pergunta da amiga sobre o porquê dos israelenses terem roubado sua terra. Conversamos a respeito, e ela lhe respondeu com um longo email contando como se sentia sobre este assunto, estabelecendo um canal de troca e entendimento, o que me fez acreditar no imenso valor destas interações tão delicadas.

\section{Referências}

ABU-NIMER, Mohammed. Conflict Resolution Approaches: Western and Middle Eastern Lessons and Possibilities. American Journal of Economics and Sociology, v. 55, n. 1, 1996, p. 35-53. Disponível em: <http://jpr.sagepub.com/content/38/6/685.short>. Acesso em: 03 jun. 2015.

AUVINEN, Ari-Matti. Social media - the new power of political influence. Centre for European Studies, 2011. Disponível em: <http://martenscentre.eu/sites/default/files/ publication-files/kansio-digital_democracy_-_final_en.pdf>. Acesso em: 06 jun. 2015.

BACHMANN, Ingrid; GUO, Lei; HARP, Dustin. The Whole Online World Is Watching: Profiling Social Networking Sites and Activists in China, Latin America, and the United
States. International Journal of Communication, v. 6, p. 298-321, 2012. Disponível em <http://ijoc.org/ojs/index.php/ijoc/article/view/1272>. Acesso em: 07 jun. 2015.

BARKAY, Rafaela. Ativismo nas mídias sociais: um olhar sobre a militância pela paz no Facebook e o conflito israelense-palestino. Revista Vértices n. 14 (2013). Disponível em: <http://revistas.fflch.usp.br/vertices/article/view/822>. Acesso em: 02 jun. 2015.

BAR-TAL, Daniel. From Intractable Conflict through Conflict Resolution to Reconciliation: Psychological Analysis. Political Psychology, Tel Aviv, v. 21, n. 2, p. 351-365, jun. 2000.

CHAITIN, Julia. Communication and safe places. Intractable Conflict Knowledge Base Website, 2003. Disponível em: <http://www.beyondintractability.org>. Acesso em: 22 maio 2014

EDMUNDS, June; TURNER, Bryan. Global Generations: social change in the twentieth century. The British Journal of Sociology, v. 56, n. 4, 2005, p. 559-77. Disponível em: <http://onlinelibrary.wiley.com/doi/10.1111/j.1468-4446.2005.00083.x/full>. Acesso em: 02 jun. 2015.

KAHN, Richard; KELLNER, Douglas. New Media and Internet Activism: From the 'Battle of Seattle' to Blogging. New Media Society, v. 6, n. 1, 2004, p. 87-95. Disponível em: <http:// nms.sagepub.com/content/6/1/87.full.pdf>. Acesso em: 02 jun. 2015.

LOTAN, Gilad. Israel, Gaza, War \& Data: social networks and the art of personalizing propaganda, 2014. Disponível em: <https://medium.com/i-data/israel-gaza-war-dataa54969aeb23e>. Acesso em: 03 jun. 2015.

RECUERO, Raquel. Curtir, compartilhar, comentar: trabalho de face, conversação e redes sociais no Facebook. Verso e Reverso, v. 28, n. 68, p. 114-124, maio-ago. 2014/2. Disponível em: <http://revistas.unisinos.br/index.php/versoereverso/article/view/ ver.2014.28.68.06>. Acesso em: 28 dez. 2015.

Social Media and Symbolic Violence. Social Media + Society, v. 1, p. 1-10, 2015. Disponível em: <http://sms.sagepub.com/content/1/1/2056305115580332.full. pdf+html>.

TRAUBMAN, Libby; TRAUBMAN, Len. Dialogue Guidelines: Changing Confrontation to Cooperation. Jewish-Palestinian Living Room Dialogue Group. Disponível em: <http:// traubman.igc.org/dialogue2.htm-Why>. Acesso em: 03 jun. 2015.

Recebido em 03/11/2015.

Aceito em 29/04/2016. 